\title{
DYNAMIC CHANNEL DECISION-MAKING OF FRESH AGRICULTURAL PRODUCT COMPANIES CONSIDERING CONSUMER CONVENIENCE PREFERENCES
}

\author{
Bo Yan*, Liguo Han, Yanru Chen and Si Liu
}

\begin{abstract}
This paper studies the strategic channel decision-making of fresh agricultural product enterprises from the perspective of consumer convenience preferences. This research is carried out under the background of the upgrading of domestic consumption and the explosion of stay-at-home economy in China in recent years. In this paper, consumers are segmented firstly according to their different preference for consumption time, namely, convenience preference. Then, a channel decision model which considers the consumer convenience sensitivity and the inconvenience cost is proposed. Finally, the optimal wholesale price and delivery lead time of the supplier and the service level decision of the retailer are obtained by using backward induction method. The results show that under different market conditions, the supplier can adopt three equilibrium strategies: NR (No Retailer), CP (Capture Profit) and SP (Share Profit). With the change of inconvenience cost, the equilibrium state of supply chain will also change. Fresh agricultural product companies can choose different strategies to maximize their revenue according to different markets.
\end{abstract}

Mathematics Subject Classification. 68U20, 90B05.

Received August 18, 2019. Accepted October 15, 2020.

\section{INTRODUCTION}

The high demand for vegetables and fruits in the dietary structure of Chinese residents has led to a large market for fresh agricultural products with little elasticity in consumer demand. According to the Chinese State Council's 2020 food consumption standards, the total demand for fresh agricultural products will reach 420 million tons, while China's annual production of fresh agricultural products in 2018 exceeded 1.11 billion tons, which means that the market has entered a period of structured oversupply and started to shift to a consumer-centric buyer's market, where all supply chain links need to be re-oriented around the final consumer.

According to data released by the National Bureau of Statistics for the four quarters ending 2019, the national online retail sales of physical goods as a percentage of total retail sales of social consumer goods is only 20.7 percent. China's urban and rural retail channels are still dominated by offline psychical channels and the online retail market still seems to be a "big cake" to be allocated. According to McKinsey's China Fresh Market Survey,

Keywords. Convenience preference, inconvenience cost, strategy of supply chain channel, supply chain management.

School of Economics and Finance, South China University of Technology, Guangzhou 510006, P.R. China.

*Corresponding author: yanbo@scut.edu.cn 
some consumers still prefer to buy fresh products from offline psychical channels such as vegetable markets or supermarkets, with online direct sales channels accounting for only 7 percent of total fresh consumption.

Fresh food is an indispensable necessity in daily life, but its daily shopping needs to take a long time. As the pace of life accelerates and leisure preferences rise, consumers' disposable time is being squeezed considerably. The increasing opportunity cost of time for some consumers has led to higher demands for the convenience of buying fresh produce. Because online channels are not limited by time and space, and can make full use of fragmented time to implement purchasing behavior, more and more consumers are trying to buy fresh produce online in order to reduce the time investment. Due to travel restrictions during COVID-19, consumers' demand for fresh goods purchased through online channels has effectively increased, with orders from fresh platforms such as MissFresh, Suning, JD, and Fresh.com increasing several times. According to the data, in March 2020, China's fresh e-commerce platform ranked first with 10.26 million people living per month.

Meanwhile, along with the youthfulness of consumers and changes in consumption habits, the strategy channel decision-making of fresh agricultural enterprises should also be changed to correspond. Several studies were conducted on channel decision making, but only a few examined this concept in specific industries, especially for the fresh agricultural industry. Compared with other industries, the natural properties of fresh produce dictate that it is perishable and fragile in storage and transport. Different fresh agricultural products may attain varied sales volume because of time window.

Thus, when fresh agricultural enterprises broaden their market reach, they should make sound supply chain decisions to meet the increasing convenience needs of consumers. This paper studies the strategic channel decision-making of fresh agricultural product enterprises from the perspective of consumer convenience preferences. In this paper, consumers are segmented firstly according to their different preferences for consumption time, namely, convenience preference. Then, a channel decision model which considers the consumer convenience sensitivity and the inconvenience cost is proposed. Finally, the optimal wholesale price and delivery lead time of the supplier and the service level decision of the retailer are obtained by using backward induction method. The rest of the paper is organized as follows. Related studies are reviewed in Section 2. Section 3 introduces the model used throughout this paper. Section 4 explores the model from the three perspectives of consumers, the physical store retailer and the supplier by backward induction method. Section 5 uses a case study to illustrate the model. Finally, Section 6 presents our conclusions and discussion.

\section{Literature REVIEW}

We mainly review two streams of literature closely related with our research. The first stream of literature focuses on channel decision-making of enterprises from the perspective of suppliers and retailers. Soleimani et al. [22] studied the optimal decision-making problem of dual-channel supply chains with simultaneous disruption of demand and production cost. Cao [3] investigated the optimal decision-making and coordination of a dualchannel supply chain when the demands of two competing end-markets were simultaneously disrupted. Yan et al. [27] studied when retailers should implement an online-to-store channel in addition to traditional brickand-mortar channel or online channel in a competitive market. Chen et al. [5] studied the dual channel strategy of a supplier with an independent traditional channel. Considering channel base demands, operational costs, and substitutability of channels. Cai [4] investigated channel selection and coordination when the reselling channel and the direct channel are available for the supplier. Balakrishnan et al. [1] examined the competition between an offline retailer and an online retailer, both of which sell a product whose valuation is uncertain for customers. They find that customer freeriding by researching the product offline but purchasing it online intensifies competition and reduces the profits of both retailers. Dan et al. [7] compared the service levels in a single supply chain and a dual-channel supply chain. Lan et al. [13] considered a supply chain in which a manufacturer distributes a product through two distributors when the demand is uncertain. The optimal ordering strategy of retailers and the optimal pricing strategy of manufacturer can be drawn. It was found that the second channel may have Pareto benefits for all participants compared to a single channel system. Li et al. [16] proposed a multi-period stochastic dynamic programming model to study the problem of a dual-channel 
inventory management operated by one supplier. Li et al. [15] considered the supplier's encroachment problem under asymmetric information with retailer's risk-averse behavior and builded a dual-channel supply chain model and obtained the optimal equilibrium results. Considering the supply chain structures and channel pricing forms, Wang et al. [25] studied the pricing and service decisions in a dual-channel supply chain which consists of two suppliers and one common retailer. Javadi et al. [11] used a dynamic multi-level Stackelberg game approach to find out the return strategy, optimal pricing and energy-saving strategies decisions based on a dual-channel supply chain model. Patel [20] studied how the level of integration of both marketing and technical assets would influence the service retail channel expansion.

The second stream of literature focuses on channel decision-making of enterprises from the perspective of consumers. Ha et al. [10] introduced the delivery frequency and price into the function of consumer utility to analyze the decisions of supply chain. Dumrongsiri et al. [8] studied the channel decisions of supplier by considering that consumers will choose the channel based on price and service quality. The results show that partners in dual-channel supply chain can reap greater benefits when consumers are sensitive to service level. Li et al. [16] examined a dual-channel supply chain for a supplier of green products; they found that when the cost of greening is higher than the threshold, the supplier should not open a direct channel. However, a dual-channel green supply chain existed when the degree of customer loyalty to the retail channel and the cost of greening satisfied certain conditions. Gensler et al. [9] applied an integrated approach toward channel choice-making. Khudri and Sultana [12] studied the determinants of service level and the impact of service level and consumer characteristics on consumer channel choice-making from the aspect of consumers. Su et al. [24] developed a price commitment model for customer strategy behavior and explored the role of price commitment strategies in mitigating customer strategy behavior. Correa et al. [6] studied a menu-type price commitment strategy related to inventory volume and found that the strategy mitigates customer strategy behavior better than traditional price commitment strategies under given conditions. Liu et al. [17] studied the dynamic pricing of competing firms when customers had strategy behavior and introduced price commitment strategies to mitigate the impact of customer strategy behavior on firm revenue. Oppewal et al. [19] used channel attributes and decision attributes to study channel mix usage by customers. This study considered all stages of the purchasing process, channel attributes, experience, and spillover effects when examining the channel choice intentions of consumers. Considering the heterogeneity of customers, the social dynamics in their behavior, and the various phases of the purchasing process, Sonderegger-Wakolbinger and Stummer [23] introduced an agent-based simulation approach to analyze the impact of multi-channel activities on customer channel choices. Maity and Dass [18] found that consumers are likely to undertake simple decision-making tasks on channels that incorporate low (e.g., m-commerce) levels of media richness; they used channels with medium (e.g., e-commerce) and high (e.g., in-store) media richness to conduct complex decision-making tasks. Zhao et al. [28] divided consumers into two types: time sensitive and price sensitive in order to study how firms in service and make-to-order manufacturing industries choose their quotation models. Similarly, Ren et al. [21] argued that the consumer utility of online channels should include the attribute of service time besides price. Xiao and Shi [26] utilized price to define the consumer utility of online channel, and transportation distance to define consumer utility of traditional offline psychical channel, to study the price and supply priority decisions in dual-channel supply chain. Table 1 summarizes the scenarios presented in the relevant literature.

In summary, the current research on dual-channel supply chain mainly focuses on two aspects: one is to study the strategies implemented by supply chain partners in different environment such as demand disruption, information asymmetry; the other is to study the supply chain decision-making problem considering consumer behavior. It can be seen that many scholars introduce price, time, service, and cost and consumer preference into the consumer utility function, so as to study the supply chain decision from the perspective of consumers.

However, this research usually does not focus on a specific industry, and consumers' behavior is closely related to the products they buy. As mentioned above, the youthfulness of consumers has different preferences for convenience when purchasing fresh agricultural products. Previous studies on convenience had favored timesaving strategies which had noted that the time factor determines the degree of convenience, and assumed that the more time a product or service can save consumers, the greater the degree of convenience. Berry et al. [2] 


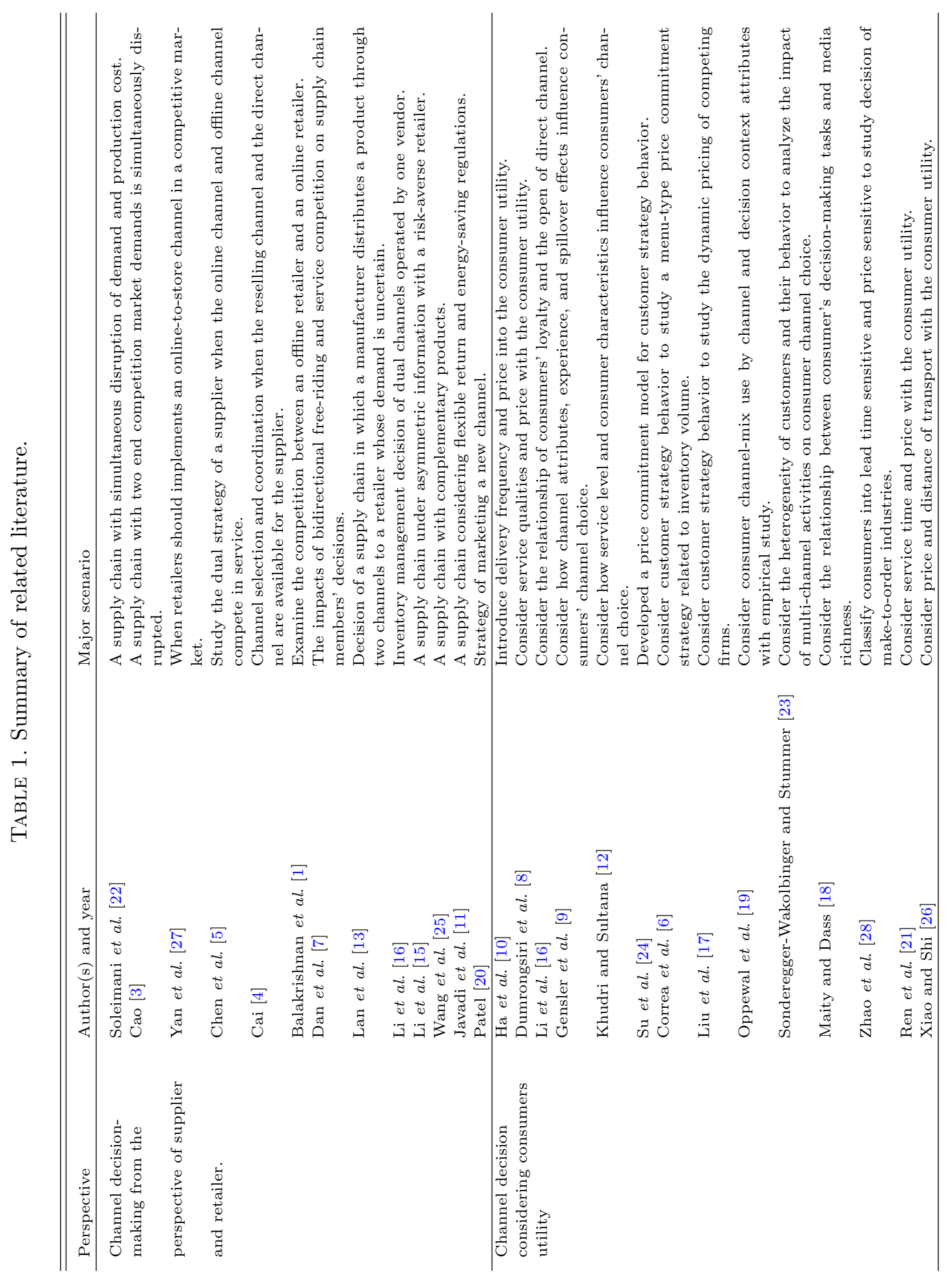


agreed that any service which helped to reduce consumer shopping time, effort, and psychological cost will help to enhance the convenience of the service. Therefore, to better explore the impact of consumers' convenience preference on ivides consthe strategy of fresh agriculture supply chain, this paper dumers into several groups, and introduces the sensitivity of consumption time into consumer utility function. Meanwhile, to represent the supply chain of the fresh agricultural market in which fresh goods are sold through dual channels, the channel differentiation is achieved through the additional delivery lead time for the online direct sales channel and the limited inventory (and the resulting probability of shortage) of the offline physical retail channel. The decisionmaking behaviors of the supplier and the retailer in different market environments are analyzed. Finally, the optimal channel decision-making under different market parameters is given.

\section{Model COnstructions}

It is assumed that a supplier sells fresh agricultural products through an online direct sales channel and an offline physical retail channel during the sales period. This is a dynamic game of complete but imperfect information. The sequence of the game is shown as follows:

Firstly, at the contracting stage, the supplier sets the wholesale price and sends an offer to the retailer. If the retailer agrees to the offer, the supplier establishes a physical retail channel to sell its products. Based on a given wholesale price, the supplier and the retailer cannot observe each other's actions when making their own decisions. The selected inventory level of the retailer can affect the service level provided to the consumer through the shortage rate of the product. At the same time, the supplier sets a product delivery lead time for the online channel without observing the retailer's decisions, which leads to simultaneous decision-making gaming problems between the supplier and the retailer.

Secondly, prior to the sales period, the supplier provides the retailer with the appropriate inventory and formulates the corresponding wholesale price contract.

Finally, during the sales period, the consumer's decision-making behavior is to decide from which channel to purchase. This behavior is mainly affected by the convenience of purchasing products from the online direct sales channel and the service level and loss in out of stock of store retailer. Consumers can also choose whether to purchase or not based on the availability of the product and the utility value that the consumer can receive as the sell price of the product changes.

At the end of the sales period, the benefits to the supplier, the retailer and consumers are all satisfied.

\subsection{Symbol description}

The parameters are divided into market and decision variable parameters The market parameters in the model are defined as follows:

$d$ : Consumer sensitivity coefficient for convenience to get fresh produce. Since the distribution of consumer demand is divided into different channels according to the distribution of consumption time sensitivity. According to the proportion of consumers with different sensitivity coefficients in the total consumers, the demand of the whole market will be divided into demand which will be satisfied by different channels. Therefore, to simplify the model, we assume that $d \in[0,1]$.

$p$ : Final selling price of fresh agricultural products.

$v$ : Utility value that the consumer can obtain from the fresh agricultural product.

$c$ : Cost of unit fresh agricultural products.

$m$ : Cost parameters of the online direct sales channel.

$k$ : Inconvenience cost, which means that consumers have to cost extra effort and time to go to physical stores and the uncertainty of inventory state may deter the consumers because they are worried about the fresh produce are out of stock when they get to the offline physical stores compared with buying products through online direct sales channel.

$a$ : Maximum of the consumer product demand in the market. 


\section{Consumers who buy form the online direct sales channel}

If the stock of traditional channel is available, the consumers buy from the offline physical stores; or they will not buy

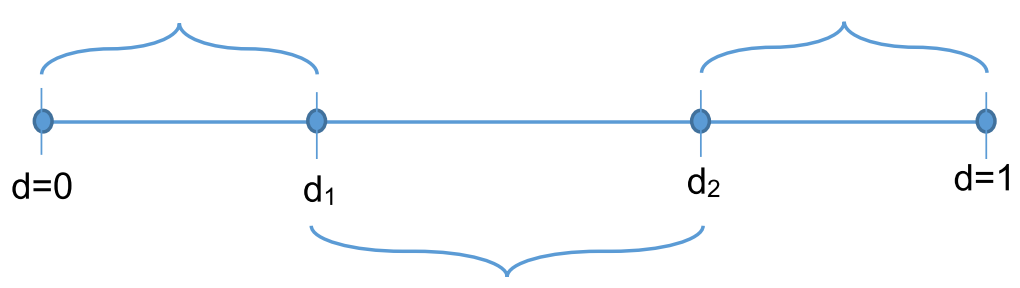

If the stock of traditional channel is available, the consumers buy from the offline physical stores; or they will buy from the online direct sales channel

Figure 1. Consumer segmented based on different values of $d$.

The main decision variables in supply chain channel are defined as follows:

$\omega$ : Wholesale price offered by the supplier to the physical store retailer.

$t$ : Consumption time, which is the time spent on buying fresh produce.

$\alpha$ : Level of service provided to the consumer by the physical store retailer, which is mainly affected by the spot supply capability of the physical store retailer.

$\varphi(\alpha)$ : Level of probability that consumers can achieve their consumption needs in a physical store, which means when a consumer chooses to buy the fresh produce from the offline physical retailer, the probability that his/her demand can be met is $\varphi(\alpha)$.

$q(\alpha)$ : Spot stock.

\subsection{Model assumptions}

(1) Considering that consumers can choose to purchase fresh produce or not through online direct sales channels or offline physical store channels and consumers can be categorized according to their convenience during the purchase process, that is, the time-saving $t$. To illustrate the heterogeneity of consumer distribution under this classification standard, we differentiate the consumers according to their sensitivity coefficients for convenience $d$, as shown in Figure 1 .

(2) The total size of market demand is $X ; X \sim U(0, a)$ ( $X$ follows uniform distribution). Total market size is affected by the change of consumer demand, which is mainly influenced by external variables, such as economic environment and government policies.

(3) When consumers with a sensitivity coefficient of $d$ buy products through the online direct sales channel, they can obtain an effective utility value of $u_{d}$, which is mainly affected by the supplier's lead time $t$.

(4) For online direct sales channel, delivery lead time $t$ can provide the supplier with adequate processing times to meet the orders.

(5) For the offline physical retail channel, when a consumer intends to purchase a fresh agricultural product an expected effective utility value $E\left(u_{r}\right)$ is used which is affected by the uncertainty of the spot supply of products and is mainly determined by the retailer's service level $\alpha$.

(6) The retailer can achieve real-time transfer of the ownership of products. Thus, waiting time does not reduce the effective utility of consumer value. However, purchasing from retail stores is inconvenient for consumers, which will reduce the effective utility of consumer value. 
Based on these assumptions, consumers will combine the difference between their convenience of purchasing products and the utility values provided by the two channels to decide which channel to buy or not to buy.

When consumers do not mind the consumption time, that is, $u_{d} \geq 0$ they will consider choosing any channel to buy products. When $u_{d} \geq E\left(u_{r}\right)$, they will choose to buy products through the online direct sales channel. This process is called the first type of demand $D_{d}^{1}$. When $u_{d}<E\left(u_{r}\right)$, they will choose to buy products through physical stores. If physical stores have spot goods, they will buy or choose to re-enter the online direct sales channels for product purchase. Production demand in this case pertains to the second type of demand $D_{d}^{2}$.

When the consumption time sensitivity of consumers is high and they do not want to wait, that is, when $u_{d}<0$, consumers will not consider the online direct sales channels. In this context, when $E\left(u_{r}\right) \geq 0$, consumers will choose to buy from physical stores. However, if physical stores are out of stock at this time, then consumers will leave and decides not to buy a product. When $E\left(u_{r}\right)<0$, they will not also buy any product. In the last two cases, the loss of consumers is the third type of demand, that is, the loss of demand. We also assume that the demand of consumers who buy in physical stores is the fourth type of demand, that is, store needs.

On the basis of a given consumption time $t$ and according to historical data, the cost of the online direct sales channel of a supplier is $\frac{m}{t^{2}}$, where $m$ is the relevant cost parameter of the online direct sales channel of a supplier. Due to the perishability of fresh agricultural products, Chinese consumers ensure the freshness of agricultural products through high-frequency purchase and a small amount of stock keeping unit (SKU) per order. Therefore, $\frac{m}{t^{2}}$ is related to the order quantity, but not to the sales volume in the online direct sales channel. Thus, we assume that $\frac{m}{t^{2}}$ includes the processing and transportation costs of the order. To provide consumers with a short consumption time $t$ (high service level), the supplier will maintain sufficient inventory, employ more workers to handle orders quickly and use faster logistics. These behaviors will lead to the high cost of online direct sales channel. The cost $\frac{m}{t^{2}}$ of direct sales channel will increase with the decrease of consumption time $t$. Another option for the supplier is to extend consumption time $t$, which means a low level of service. At this time, suppliers can employ fewer workers to handle orders and use cheaper delivery methods to meet consumer demands.

\section{Model ANALYSiS}

This study analyzes the model in Section 3 by backward induction, which involves three steps. First, we obtain the total expected demand of both channels. Then, we study the Nash equilibrium point in production decision game and obtain the optimal response functions of the supplier and the traditional retailer. Finally, we obtain the best decision and wholesale price of the supplier.

\subsection{Channel choice for consumers}

The total demand of the market is achieved through online direct sales channel and offline physical retail channel. The percentage of consumers distributed in both channels is mainly influenced by the level of service $\alpha$ provided by the offline physical stores and the consumption time of the online direct sales channel $t$. This difference is described by comparing the effective utility values given to consumers through the introduction of different channels. On the basis of this comparison, the market segments of different channels are identified.

To simplify the model and focusing on how consumption time affects the consumer' channel choice, we assume that the utility function is linear in price and time effects [17]. For consumers with convenience of purchasing products sensitivityd, the effective utility value function obtained from online direct sales channel is given as:

$$
u_{d}=v-p-d t
$$

where $v$ is the value that consumers can obtain from the product, and $p$ is the price of the product; $v>p ; d t$ indicates that an increase in the convenience sensitivity $d$ to the consumer or consumption time $t$ will reduce the effective utility value of the consumer. For consumers with a convenience sensitivity of $d$, the effective utility value function obtained from offline physical retail channels is given as:

$$
E\left[u_{r}\right]=\varphi(\alpha)(v-p)-k .
$$


TABle 2. Demand distribution under different consumption times.

\begin{tabular}{lllll}
\hline \hline Range of consumption time $t$ & $t \leq t^{e}$ & $t \in\left(t^{e}, v-p\right]$ & $t \in(v-p+\infty$ & $t \rightarrow+\infty$ \\
\hline Status of physical stores & Close & Running & Running & Running \\
Coverage of online direct sales channel & $100 \%$ & $100 \%$ & A part & 0 \\
Demand of offline physical stores channel $D_{r}$ & 0 & $\left(1-d_{1}\right) X$ & $\left(1-d_{1}\right) X$ & $X$ \\
First type of demand $D_{d}^{1}$ & $X$ & $d_{1} X$ & $d_{1} X$ & N/A \\
Second type of demand $D_{d}^{2}$ & N/A & {$\left[D_{r}-q\right]^{+}$} & $\frac{d_{2}-d_{1}}{1-d_{1}}\left[D_{r}-q\right]^{+}$ & N/A \\
Loss of demand & N/A & 0 & $\frac{1-d_{2}}{1-d_{1}}\left[D_{r}-q\right]^{+}$ & {$\left[D_{r}-q\right]^{+}$} \\
\hline
\end{tabular}

Notes. N/A means "Not Applicable".

The value of consumer-expected effective utility is affected by the uncertainty of the spot supply capacity of offline physical retail channel; $\varphi(\alpha)$ refers to the level of probability that consumers can realize their consumption demands in physical stores, which is mainly influenced by service level $\alpha$ of the retailer. We obtain $\varphi(\alpha)$ in Lemma 4.2. When $E\left[u_{r}\right]<0$, consumers will not choose to buy from the offline physical retail channel. We must set the minimum service level of physical stores:

$$
\varphi(\alpha) \geq \frac{(v-p)}{k} .
$$

Therefore, we assume that the minimum service level of the physical stores meets the following regional distribution.

$$
\alpha_{\min }=\min \left\{\alpha \in[0,1] \mid \varphi(\alpha)=\frac{(v-p)}{k}\right\} .
$$

The distribution of consumer demand is divided into different channels according to the distribution of consumer convenience sensitivity, assuming that

$$
\begin{aligned}
& d_{1}=\min \left\{\left\{d \mid u_{d}=E\left[u_{r}\right]\right\}, 1\right\}=\min \left\{\frac{[(v-p)(1-\varphi(\alpha))+k]}{t}, 1\right\} \\
& d_{2}=\min \left\{\left\{d \mid u_{d}=0\right\}, 1\right\}=\min \left\{\frac{v-p}{t}, 1\right\} .
\end{aligned}
$$

When the consumer convenience sensitivity is low, they can obtain high effective utility value through the online direct sales channel. When the consumer convenience sensitivity is lower than $d_{1}$, they will choose to buy from the online direct sales channel; at this time $u_{d} \geq E\left[u_{r}\right]$. When the consumer convenience sensitivity is higher than $d_{1}$, they will choose to buy from offline physical retail stores. However, if the physical stores are out of stock at this time and the consumer convenience sensitivity is not higher than $d_{2}$, then they will come back and buy through the direct channel; at this time $u_{d} \geq 0$. Moreover, if the physical stores are out of stock and the consumer convenience sensitivity is higher than $d_{2}$, then consumers will not buy this product; thus $u_{d}<0$.

We draw the following lemmas on the basis of the market demand assumption and derivation presented above.

Lemma 4.1. The distribution of demand for direct channel and physical retail channel is shown in Table 2 on the basis of random distribution of the total market demand.

The market demand of the online direct sales channel is $D_{d}^{1}=d_{1} X$ and the market demand of the offline physical store channel is $D_{r}=\left(1-d_{1}\right) X$. If the demand of physical stores is not greater than the inventory level, that is, $D_{r} \leq q$, then the store can meet the needs of all consumers. If the demand of physical stores is greater than its inventory level, that is, $D_{r}>q$, then $\left[D_{r}-q\right]^{+}$units of needs cannot be satisfied. In the 


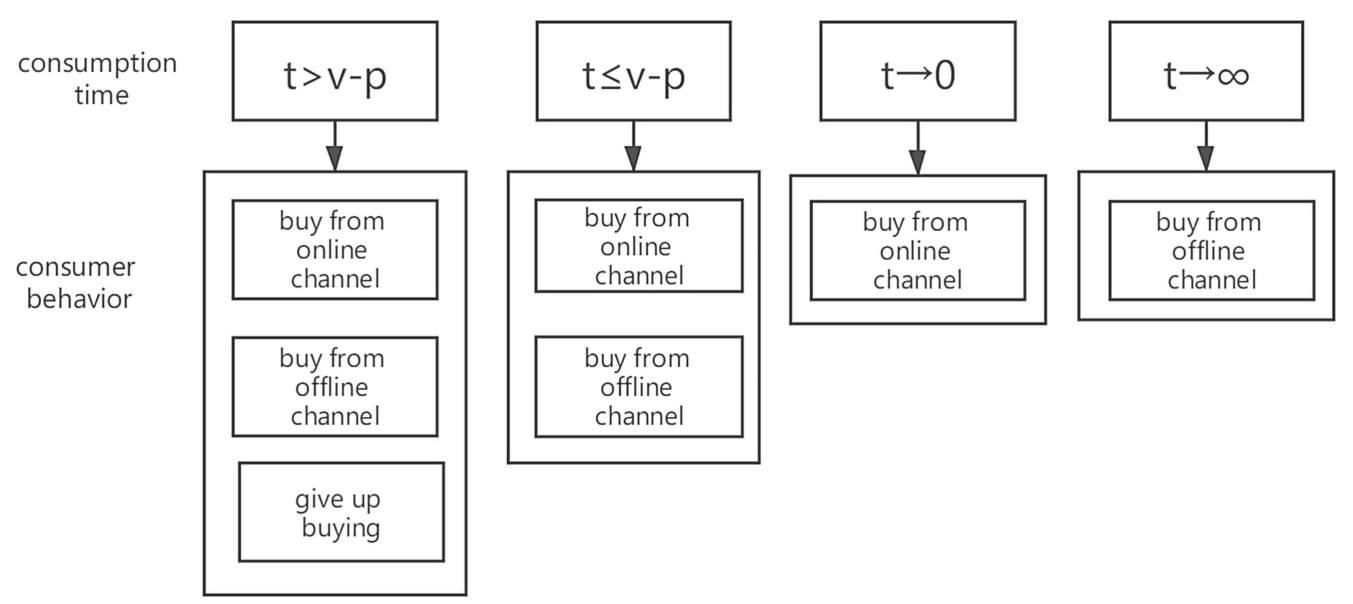

Figure 2. Consumer choices with different consumption time.

$\left[D_{r}-q\right]^{+}$unit, $\frac{d_{2}-d_{1}}{1-d_{1}} \%$ consumers meet $u_{d} \geq 0$; then, this part of the consumers will choose to buy from a direct channel and constitute the second type of demand. The remaining proportion $\frac{1-d_{2}}{1-d_{1}} \%$ of consumers meet the condition $u_{d}<0$, such that they will give up buying this product and constitute the third type of demand, that is, the loss of demand.

From Lemma 4.1, we can classify the consumers in the market into three, two, or even one region according to the level of service $\alpha$ provided by physical stores and the consumption time $t$ set by the online direct sales channel. Figure 2 summarizes the consumer behavior with different consumption time.

First, market segmentation is divided into three regions. By setting the consumption time $t$ to $t>v-p$, $d_{2}<1$. The supplier can classify the consumers into three areas: consumers who meet their demands through online direct sales channel, consumers who meet their demands through offline physical stores and consumers who give up buying a product.

The supplier can also classify the consumers into two regions by setting the consumption time $t$ to $t \leq v-p$ (at this point, $d_{2}=1$ ), at which point the supplier can meet all consumers' needs through both channels, that is, all consumers can obtain positive effective utility values from both channels.

When the supplier sets the consumption time $t$ to a particularly short time, it can satisfy all the consumers in the market only through its online direct sales channel. At this time, $d_{1}=1$. Specifically, when supplier consumption time $t$ meets condition $t \leq t^{e}, t^{e}=(v-p)[1-\varphi(\alpha)]+k$, then all consumers buy a product through the online direct sales channel, and the offline physical stores have no effect. A similar case happens when the consumption time $t$ tends to approach infinity, that is, $t \rightarrow \infty\left(d_{1}=d_{2}=0\right)$, consumers can only buy through offline physical stores, and the online direct sales channel does not work.

Furthermore, the spot supply capacity of the offline physical stores affects the channel distribution of consumers in the market to a certain extent. When $\varphi(\alpha)=\frac{v-p}{k}$ and $t>v-p$, that is, $d_{1}=d_{2}<1$, consumers who first choose to purchase from physical stores will not choose to buy products from the online direct sales channel when they find that offline physical stores are out of stock. Thus, the second type of demand $D_{d}^{2}$ will not exist.

\subsection{Decision of physical store retailer}

On the basis of the consumption time of $t$ in the online direct sales channel, we can obtain the best service level of the retailer $\alpha(t)$ through the following steps. First, we can deduce the retailer's order quantity, spot supply ability, and expected sales volume based on a given service level. At this time, the retailer service level is $\alpha=\operatorname{Pr}\left(D_{r} \leq q\right)$. The following lemma exists. 


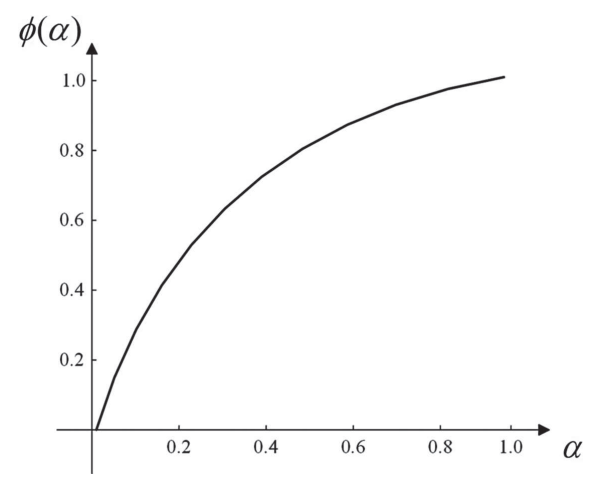

FigURE 3. Relationship between service level and spot supply capacity in physical stores.

Lemma 4.2. For a given service level $\alpha$,

(1) The optimal order size of the retailer to the supplier is $q(\alpha)=a \alpha\left(1-d_{1}(\alpha)\right)$ unit.

(2) The corresponding probability that consumers' demand can be met from physical retailer is $\varphi(\alpha)=\alpha(1-\ln (\alpha))$, that is, the retailer's ability of providing spot product to consumers is $\varphi(\alpha)=\alpha(1-\ln (\alpha))$.

(3) The expected sales volume of the retailer is

$$
E\left[\min \left\{D_{r}, q\right\}\right]=a\left(1-d_{1}(\alpha)\right)\left(\alpha-\alpha^{2} / 2\right)=q\left(1-\frac{\alpha}{2}\right) .
$$

The second part of Lemma 4.2 describes the corresponding relationship between service level $\alpha$ and spot supply capacity $\varphi(\alpha)$. In the preceding theoretical assumption, retailer service level $\alpha$ is defined as the probability that the retailer is not out of stock in the sales cycle. Figure 3 describes the difference between service level $\alpha$ and spot supply capacity $\varphi(\alpha)$.

As shown in Figure 3, when $\alpha=0.6, \varphi(\alpha)=0.846 ; \alpha=0.6$ means that the physical store retailer has a 0.6 probability of meeting the demands of all consumers. The retailer has 0.4 probability of failing to meet consumer demands, that is, a shortage of spot. When the physical store retailer is out of stock, the demands of first-come consumers will be met, and the demands of the following consumers will not be met. The second part of Lemma 4.2 explains that when a consumer is ready to buy a product from a physical store, his demand can be effectively met of 0.846 . Moreover, the value of spot supply capacity $\varphi(\alpha)$ in this model is greater than the value of service level $\alpha$ because even if the store is out of stock, the needs of consumers who previously reached the store can still be met during its sales cycle.

A higher level of service will require the physical store retailer to place more orders with the supplier. This will have two primary purposes: First, more inventories will help the retailer to avoid the probability of out-ofstocks and meet more of consumer demand. Second, more inventory will attract more consumers. As shown in Figure 3, the retailer will obtain a large market segmentation rate through high quality service level. Therefore, more orders can help the retailer increase market share and reduce the probability of out-of-stock.

For a given service level $\alpha$, the expected return equation of the store retailer is as follows:

$$
\pi_{r}(\alpha)=p E\left[\min \left\{D_{r}, q\right\}\right]-w q .
$$

For a physical store retailer, that consumer demand is greater than its inventory will lead to the loss of sales. If consumer demand is less than its inventory, then the residual value of remaining inventory will not be calculated at the end of the sales season. According to Lemma 4.2, the expected return can be deformed as

$$
\pi_{r}(\alpha)=a \alpha\left(1-d_{1}(\alpha)\right)\left(p-w-p \frac{\alpha}{2}\right) .
$$


From Lemma 4.1, $D_{r}$ is the division function of the market demand and the expected return of physical store retailer can be deformed by combining with equation (4.5).

$$
\max \pi_{r}(\alpha)=\frac{a \alpha}{t}\{[t-k-(v-p)(1-\alpha(1-\ln \alpha))]\}\left(p-w-p \frac{\alpha}{2}\right) .
$$

$\alpha \in\left\{\alpha_{0},\left[\alpha_{\min }, 1\right]\right\}$, where $\alpha_{\min }$ can be obtained by equation (4.4) and $d_{1}\left(\alpha_{0}\right)=0$. The condition can not only avoid $\ln \alpha$ from approaching negative infinity but also make $q\left(\alpha_{0}\right)=0$ by selecting a proper $\alpha_{0}$, that is, the optimal order size of retailers is 0 and the expected profit is $0 ; p-w$ refers to the marginal profit that the retailer can obtain by selling a unit product; $p \frac{\alpha}{2}$ can be understood as in the service level $\alpha$; and service cost per unit of product should be paid by the retailer because of the inventory. Proposition 4.3 describes the optimal response of physical store retailer.

Proposition 4.3. The profit function of a physical store retailer has local optimal solution in the range of consumption time $t \in(0,+\infty)$. If the local optimal solution is $\alpha_{i}(t)$, then it will decrease with the increase of the wholesale price $\omega$. At this time, the best solution of the retailer is

$$
\alpha^{*}(t)= \begin{cases}\alpha_{\min } & \alpha_{i}(t) \leq \alpha_{\min } \\ \alpha_{i}(t) & \alpha_{i}(t) \leq\left(\alpha_{\min }, 1\right) \\ 1 & \alpha_{i}(t) \geq 1\end{cases}
$$

$\pi_{r}\left(\alpha^{*}(t)\right) \geq 0$ should be ensured, or $\alpha^{*}(t)=\alpha_{0}$.

A high wholesale price $\omega$ will reduce the inventory level of the physical store; therefore, the service level will decrease, that is, the optimal service level of the retailers will decrease with the increase of the wholesale price. On the contrary, the low wholesale price $\omega$ will increase its service level. If the wholesale price $\omega$ is too high, then the retailer will set $\alpha^{*}(t)=\alpha_{0}$ and will not order from the supplier.

Corollary 4.4. If the supplier sets consumption time as $t=+\infty$, then the supplier closes the online direct sales channel. At this time, the optional reaction of offline physical store retailer is $\lim _{t \rightarrow \infty} \alpha^{*}(t)=\max \left\{\alpha_{\min }, \frac{p-\omega}{p}\right\}$.

When the offline physical store retailer does not face the influence of online direct sales channel, they do not need to consider the level of service and the demand decision because all consumers have only one channel to buy from at that time. Thus, consumers will choose to buy from this store as long as their service level is not lower than the lowest value $\alpha_{\min }$. Thus, the critical ratio of the general optimal service level of a store retailer is $\frac{p-\omega}{p}$, unless the ratio is lower than the minimum value $\alpha_{\min }$.

\subsection{Decision of the supplier}

In this section, we discuss optional consumption time $t^{*}(\alpha)$ of the supplier based on the given service level $\alpha$ of the retailer. From Lemma 4.5, we can know that the total sales volume of the online direct sales channel is composed of the first and second types of demand. Thus, we can get the profit function of the supplier as follows:

$$
\max _{t} \pi_{m}(t)=(\omega-c) q+(p-c) E\left[D_{d}^{1}+D_{d}^{2}\right]-\frac{m}{t^{2}} .
$$

The function presented above describes the gain and loss of the supplier in different channels. On the one hand, the marginal revenue of online direct sales channel $(p-c)$ is higher than that of the offline physical channel $(\omega-c)$. On the other hand, when the supplier chooses online direct sales channel, it will face market uncertainty. However, if the supplier chooses the offline physical channel, it can transfer the uncertainty of the market to the physical stores because the offline physical channel cannot return its residual products to the supplier. Therefore, when considering this problem, the supplier should not only take into account the distribution of products between channels but also consider the cost of online direct sales channel $\frac{m}{t^{2}}$.

The following lemma describes the expected sales of online channel and the expected return function of the supplier. 
Lemma 4.5. The expected sales of online channel is

$$
E\left(D_{d}^{1}+D_{d}^{2}\right)=\frac{a}{2}\left\{\alpha(\alpha-2)\left[d_{2}(\alpha)-d_{1}(\alpha)\right]+d_{2}(\alpha)\right\}
$$

and the expected return function of the supplier is a continuous function, which is mainly shown as follows:

$$
\pi_{m}(t)= \begin{cases}\pi_{m}^{e}(t) \equiv \frac{a}{2} \times(p-c)-\frac{m}{t^{2}} & t \leq t^{e} \\ \pi_{m}^{a}(t) \equiv a(\omega-c) \alpha+\frac{a(p-c)(1-\alpha)^{2}}{m}+\frac{1}{t} G^{a}(\alpha)-\frac{m}{t^{2}} & t \in\left(t^{e}, v-p\right] . \\ \pi_{m}^{u}(t) \equiv a(\omega-c) \alpha+\frac{1}{t} G^{u}(\alpha)-\frac{m}{t^{2}} & t>v-p\end{cases}
$$

In this function,

$$
\begin{aligned}
& G^{a}(\alpha)=\frac{a \alpha}{2} \times\{(v-p)[1-\alpha(1-\ln (\alpha))]+k\} \times[(p-c)(2-\alpha)-2(\omega-c)], \\
& G^{u}(\alpha)=\frac{a \alpha}{2} \times\{(v-p)[1-\alpha(1-\ln (\alpha))]+k\} \times[(p-c)(2-\alpha)-2(\omega-c)]+\frac{\left[a(p-c)(v-p)(1-\alpha)^{2}\right]}{2} .
\end{aligned}
$$

The three values for consumption time $t$ are mainly derived from Lemma 4.1. By taking into account that the online direct sales channel will cover all consumer groups when the consumption time is set to $t=(v-p)$ and by setting the consumption time $t$ below $(v-p)$, the supplier will now increase the market share of the online direct sales channel by reducing the market share of retail outlets in the offline physical store. Considering the limit point, when the consumption time $t \leq t^{e}$, the offline physical store retail channels can be completely canceled. Lemma 4.6 elaborates the return functions $\pi_{m}^{a}(t)$ and $\pi_{m}^{u}(t)$.

Lemma 4.6. (1) When $G^{a}(\alpha) \leq 0, \pi_{m}^{a}(t)$ is an increasing function of consumption time $t$; when $G^{a}(\alpha)>0$, $\pi_{m}^{a}(t)$ is a function about $\alpha$ with unimodal distribution, which will have the maximum point while $t_{f}^{a}=\frac{2 m}{G^{a}(\alpha)}$.

(2) When $G^{a}(\alpha) \leq 0, \pi_{m}^{u}(t)$ is an increasing function of delivery lead time $t$; when $G^{a}(\alpha)>0, \pi_{m}^{u}(t)$ is a function about $\alpha$ with unimodal distribution, which will have the maximum point while $t_{f}^{u}=\frac{2 m}{G^{u}(\alpha)}$.

(3) When $\alpha=1, \pi_{m}^{a}(t)=\pi_{m}^{u}(t)$.

(4) When $\alpha<1$, if $t=(v-p)$, then $\pi_{m}^{a}(t)=\pi_{m}^{u}(t)$; if $t<(v-p)$, then $\pi_{m}^{a}(t)<\pi_{m}^{u}(t)$; if $t>(v-p)$, then $\pi_{m}^{a}(t)>\pi_{m}^{u}(t)$.

Lemmas 4.5 and 4.6 describe the optional response function of the supplier so that we can get Proposition 4.\%.

Proposition 4.7. On the basis of the given wholesale price $\omega$, for different service levels $\alpha$ of offline physical channel, the optional response of supplier is

$$
t^{*}(\alpha)= \begin{cases}t^{e} & \text { if } G(\alpha)>0 \text { and } t_{f}^{a} \leq t^{e} \\ t_{f}^{a}=\frac{2 m}{G^{a}(\alpha)} & \text { if } G^{a}(\alpha)>0 \text { and } t_{f}^{a} \in\left(t^{e}, v-p\right) \\ v-p & \text { if } G^{u}(\alpha)>0 \text { and } t_{f}^{u} \leq v-p \text { and }\left[t_{f}^{a}>v-p \text { or } G^{a}(\alpha) \leq 0\right] . \\ t_{f}^{u}=\frac{2 m}{G^{u}(\alpha)} & \text { if } G^{u}(\alpha)>0 \text { and } t_{f}^{u}>v-p \\ \infty & \text { if } G^{u}(\alpha) \leq 0\end{cases}
$$

The optimal delivery lead time of the supplier can be divided into five segments. According to Lemma 4.1, when the supplier's delivery lead time is less than or equal to $t^{e}$, the offline physical channel is not required to run at this moment. In other words, the supplier can set a very short consumption time to eliminate the offline physical channel and only through its online direct sales channels to serve all consumers. However, the process requires not only the logistics technical innovation, but also the large investment cost. Another limitation is that when the supplier sets the delivery lead time to infinity, that is $t^{*} \rightarrow \infty$, and the supplier closes its online direct sales channel, only the offline physical channel will run. Only a part of consumers' needs will be satisfied because the service level of the physical stores is different. The direct and traditional channels will run at the same time when the supplier sets the delivery lead time to $t^{*}=v-p$ or $t^{*}=t_{f}^{a}$. In addition, the supplier can make all consumers consider the online direct sales channel in their shopping decision by setting the consumption time $t$. At the same time, when $t^{*}=t_{f}^{u}$, the supplier can satisfy some consumers' needs through its direct channel, so a loss of demand exists. 
TABLE 3. Parameter value intervals.

\begin{tabular}{llll}
\hline \hline Parameter & Low & Middle & High \\
\hline$m$ & 1000 & 5000 & 10000 \\
$v$ & 4 & 8 & 12 \\
$p / v$ & 0.25 & 0.5 & 0.75 \\
$k /(v-p)$ & 0.125 & 0.5 & 0.75 \\
$c / p$ & 0 & 0.25 & 0.5 \\
\hline
\end{tabular}

Notes. For $p<v, k<(v-p)$, and $c<p$, so, we use parameters $p / v, k /(v-p)$, and $c / p$ instead.

TABLE 4. Parameter combinations.

\begin{tabular}{|c|c|c|c|c|c|c|c|c|c|c|c|c|c|}
\hline \multicolumn{5}{|c|}{ Market parameters } & \multicolumn{3}{|c|}{ Decision variables } & \multicolumn{2}{|c|}{ Profits } & \multicolumn{3}{|c|}{ Sales amount } & \multirow[t]{2}{*}{ Equilibrium } \\
\hline$m$ & $v$ & $p$ & $k$ & $c$ & $\omega$ & $t$ & $\alpha$ & $\pi_{m}$ & $\pi_{r}$ & Direct & Retail & Losses & \\
\hline 1000 & 4 & 1 & 0.38 & 0.00 & 1.00 & 3.00 & 0.03 & 389 & 0 & 500 & 0 & 0 & NR \\
\hline 1000 & 12 & 3 & 4.50 & 0.75 & 2.73 & 9.00 & 0.19 & 1113 & 0 & 500 & 0 & 0 & NR \\
\hline 5000 & 12 & 6 & 3.00 & 3.00 & 5.44 & 6.00 & 0.19 & 1361 & 0 & 500 & 0 & 0 & NR \\
\hline 1000 & 4 & 2 & 1.00 & 1.00 & 1.80 & 2.85 & 0.19 & 272 & 1 & 351 & 51 & 99 & $\mathrm{CP}$ \\
\hline 5000 & 4 & 3 & 0.75 & 1.50 & 2.42 & 25.11 & 0.38 & 360 & 2 & 20 & 297 & 183 & $\mathrm{CP}$ \\
\hline 10000 & 8 & 6 & 1.50 & 1.50 & 4.84 & 10.28 & 0.38 & 1372 & 4 & 97 & 249 & 154 & $\mathrm{CP}$ \\
\hline 5000 & 4 & 1 & 0.38 & 0.50 & 0.77 & 19.85 & 0.24 & 77 & 24 & 61 & 191 & 248 & SP \\
\hline 5000 & 8 & 6 & 1.00 & 0.00 & 3.72 & 3.90 & 0.43 & 1923 & 271 & 206 & 214 & 80 & SP \\
\hline 10000 & 4 & 3 & 0.50 & 0.75 & 1.89 & 31.30 & 0.37 & 435 & 200 & 14 & 296 & 191 & SP \\
\hline
\end{tabular}

\section{CASE STUdY}

\subsection{Analysis Methods}

According to the analysis presented above, with the supplier's decision of consumption time solved in Section 4.3 and retailer's decision of service-level solved in Section 4.2, the expected sales volume and corresponding profit of each channel can be obtained. We can solve the problem of channel decision-making under arbitrary condition with different parameter combinations on the basis of the mathematical model. Here, the maximum market capacity can be fixed at $a=1000$ without loss of generality.

The results are discussed in three parts. First, three types of equilibrium are analyzed. Each equilibrium is distinct due to its market parameters, and each equilibrium is also the optimal supplier channel decision-making under corresponding market parameters. Second, through examples of total cost $m$ and retailer inconvenience cost $k$ (penalty of losing sales and credit led from time windows of unsatisfied consumer needs) on the online direct sales channel, how to make the optimal channel decision-making of the supplier is illustrated. Finally, the relationship is explained between the decisions of the supplier and the retailer and the corresponding profits and the inconvenience cost $k$ of the retailer on direct sales channel.

\subsection{Segments of market}

We divide the value interval of each parameter into three levels (low, middle, and high) so that the three subintervals cover the whole interval. Considering that five parameters exist, we end up with $3^{5}=243$ parameter combinations, each of which correspond to different channel decision-making under different market conditions (Tabs. 3 and 4).

Evidently, three statuses of equilibrium are presented: 
TABLE 5. Supplier's optimal channel decisions-making with $v=8, p=4$, and $c=1$.

\begin{tabular}{lllllllllllllll}
\hline \hline & \multicolumn{10}{c}{} \\
\cline { 2 - 14 } & 0 & 0.20 & 0.40 & 0.60 & 0.80 & 1.0 & 1.20 & 1.40 & 1.60 & 1.80 & 2.00 & 2.20 & 2.40 & 2.60 \\
\hline 20000 & SP & SP & SP & SP & SP & SP & SP & SP & SP & SP & CP & CP & CP & CP \\
17500 & SP & SP & SP & SP & SP & SP & SP & SP & SP & SP & CP & CP & CP & CP \\
15000 & SP & SP & SP & SP & SP & SP & SP & SP & SP & SP & CP & CP & CP & CP \\
12500 & SP & SP & SP & SP & SP & SP & SP & SP & SP & SP & CP & CP & CP & CP \\
10000 & NR & NR & NR & NR & SP & SP & SP & SP & SP & SP & CP & CP & CP & CP \\
7500 & NR & NR & NR & NR & NR & NR & NR & NR & NR & SP & CP & CP & CP & CP \\
5000 & NR & NR & NR & NR & NR & NR & NR & NR & NR & NR & NR & NR & NR & CP \\
2500 & NR & NR & NR & NR & NR & NR & NR & NR & NR & NR & NR & NR & NR & NR \\
0 & NR & NR & NR & NR & NR & NR & NR & NR & NR & NR & NR & NR & NR & NR \\
\hline
\end{tabular}

(1) No retailers (NR). Under this equilibrium status, $d_{1}=d_{2}=1$, i.e., the supplier only sell fresh agricultural products through online direct sales channel. The Supplier offers relatively high wholesale price $\omega$ with relatively short consumption time $t$ and sale price $p$. Meanwhile, the physical retailer withdraws from the market by obtaining stock level at 0 (or by setting service level in order that $d_{1}(\alpha)=1$ ). In this equilibrium status, the supplier meets all the consumer demands without dividing the consumer group by online direct sales channel.

(2) Capture profit (CP). Under this equilibrium status, $d_{1}=d_{2}<1$. The supplier constrains physical retailer's profit to merely positive amount by setting a relatively high wholesale price $\omega$, in which way the supplier grasps all the profits from the retailer. Under these conditions, the offline physical retailer can only maintain the minimum service level $\alpha_{\min }$, and consumers are classified into two groups. The convenience-sensitive coefficient of the first consumer group $d$ is under the constraint $d<d_{1}$. People in this group will buy through the online direct sales channel, whereas people in the second consumer group buy products from the offline physical retailer if stocks are available; otherwise, they will depart from the system without buying the product. Thus, the supplier's decision meets demands of some consumers in this case.

(3) Profit sharing (SP). Under this equilibrium status, $d_{1}<d_{2}<1$. In other words, the supplier chooses dual-channel strategy and is willing to share profits with the retailer. Consumers are then segmented into three groups. The convenience-sensitive coefficient of the first consumer group $d$ is under the constraint $d \leq d_{1}$. People in this group will buy products in the online direct sales channel. The convenience-sensitive coefficient of the first consumer group $d$ is under the interval $d \in\left(d_{1}, d_{2}\right]$. People in this group will choose to check the retailer first and return to the online direct sales channel if there is no stock. The conveniencesensitive coefficient of the first consumer group $d$ is under the constraint $d>d_{2}$. People in this group will not return to the online direct sales channel but leave the system if no products are provided by the retailer. Under this status, the supplier's wholesale price $\omega$ is relatively low compared with product market price $p$.

The three equilibrium states presented above correspond to the channel strategies of suppliers under different market conditions. Under the market environment with different market parameters, the supplier can introduce an optimal channel strategy for this market environment by setting a different wholesale price in the stage of contract construction with a retailer in a physical store. In the following, the optimal channel decision-making for the supplier will be illustrated by sensitivity analyses on different online direct sales channel cost $m$ and the offline physical retailer's inconvenience cost $k$. Table 5 shows the supplier's optimal channel decision-making with different $m$ and $k$.

As shown in Table 5, the market is mainly divided into three segments (NR, SP and CP). The similar segments can be obtained when we use other values into the market parameters, such as unit product cost $c$, market selling price $p$, and consumer utility value $v$. As shown in Figure 4, the marginal impact of market parameters is illustrated, such as $c, p$, and $v$ on the decision region. 


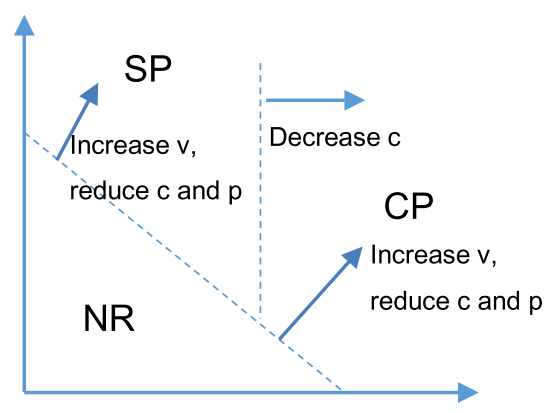

FiguRE 4. Division of market decision.

When online direct sales channel cost $m$ and out-of-stock cost of offline physical retailers $k$ are both large, the supplier will choose to sell its products through dual channels and will reap full profits. The supplier will also choose to sell its products through dual channels when the cost of online direct sales channel $m$ is high and the out-of-stock cost of physical retailer $k$ is relatively low. However, a revenue-sharing contract will be formed with the store retailer. The difference between the two equilibria mainly relies on the supplier's wholesale price $\omega$ to the store retailer. However, the supplier may choose to sell its products only through the direct sales channel without a physical retail channel when the direct channel cost $m$ and the out-of-stock cost of physical retailer $k$ are relatively small.

Figure 4 shows how other market parameters in the model can affect the change between decision-making equilibria. Decrease in unit product $\operatorname{cost} c$ and market selling price $p$, and increase in consumer utility values $v$ all will drive the supplier from NR to the other two equilibria. Moreover, Reducing unit product $\operatorname{cost} c$ will improve the supplier's power, and make it change from sharing revenue with the retailer to obtaining most profits.

\subsection{Sensitivity of market parameters}

We then analyze the sensitivity of decision variables, including wholesale price $\omega$, consumption time $t$, the service level of physical retailer $\alpha$ and the corresponding profits. First, how the decision variables change during the equilibrium strategy state transition is briefly described. When the retailer's inconvenience cost $k$ is at a relatively low level, for the supplier, the retailer is the main competitor in the direct sales channel. In this case, the supplier will set a short lead time to promote online direct sales channels. When the retailer's inconvenience cost $k$ increases to the median value, the retailer will choose to improve its service level to attract more consumers. When the inconvenience cost $k$ increases to a relatively high value, the retailer will maintain at the minimum service level limit to suppress the increase of $k$. Given this condition, the supplier will sell more products through the retailer's channel and raise the wholesale price $\omega$ to obtain most of the profits of the supply chain. Similarly, a high lead time $t$ offered by the supplier will reduce the proportion of the direct channel sales.

When other market parameters are fixed, the influences of inconvenience costs $k$ on equilibrium status and decision variables are presented in Figure 5.

As shown in Figure 5a, the supplier tends to lower wholesale price $\omega$ to support the retailer with the increase of inconvenience cost $k$. When the increase trend continues and the supplier' strategy approaches SP, wholesale price $\omega$ will experience a plunge. If the trend goes on, then the strategy will change from SP to CP. Wholesale price will somewhat jump a bit compared with SP at the beginning, but the decrease speed of $\omega$ is much faster than that of the other two strategies. After a certain point, wholesale price remains smaller than any points under other two strategies.

As shown in Figure 5b, consumption time $t$ keeps increasing on the whole with the increase of inconvenience cost $k$. The slope is less steep in status NR and SP. The increasing speed is high in CP because the retailer 


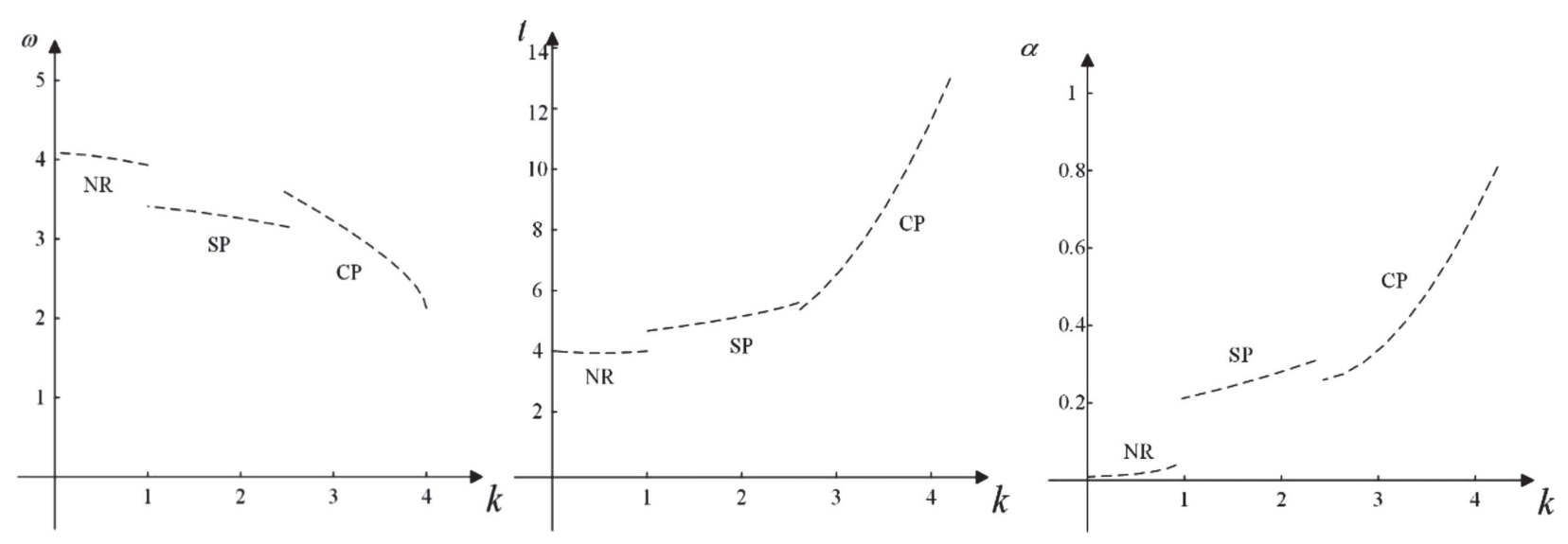

FiguRE 5. Influences of inconvenience cost $k$ on market parameters.

maintains the minimum service level limit to suppress the increase of $k$. Thus, the supplier will sell more products through the retailer's channel and raise the wholesale price $\omega$ to obtain most of profits of the supply chain. The high lead time $t$ offered by the suppliers will reduce the proportion of the direct channel sales.

As shown in Figure 5c, with the increase of inconvenience cost $k$, a high enthusiasm is shown in the traditional physical retailer due to profit sharing when the supplier's strategy changes from NR to SP. Therefore, service level $\alpha$ increases obviously in this condition. As mentioned before, when the strategy changes from SP to CP, wholesale price will experience a jump. The relatively high wholesale price leads to the plunge of service level $\alpha$. Then, it follows the increase of service level $\alpha$ from retailer's avoidance of paying the increasing inconvenience cost $k$.

Figure 6 shows how changes of retailer's inconvenience cost $k$ influence profits of the supplier and the retailer and sale amounts.

Figure 6a illustrates influences on profits of the supplier from changes in inconvenience costs $k$. With the increase of $k$, the profit is increasing. The growth rate increases significantly when the status changes from SP to $\mathrm{CP}$, which sees influences of inconvenience cost $k$ on the retailer's profit, as shown in Figure $6 \mathrm{~b}$. When the supplier is forced to adjust its strategy to $\mathrm{CP}$ or NR equilibrium to accommodate inconvenience cost $k$, the retailer's profit becomes extremely small. Moreover, the retailer's profit will turn out to be relatively significant when the value of inconvenience cost $k$ encourages the supplier to take advantage of SP strategy.

Figures $6 \mathrm{c}$ and $6 \mathrm{~d}$ describe the sales volume fluctuation in terms of various inconvenience costs $k$ in the two sales channels. Consumer demands are mainly satisfied through online direct sales channel when the supplier seeks for NR strategy under certain inconvenience cost $k$ intervals, whereas the channel changes to direct selling and retail outlets when SP strategy is used. The same channels are devoted with CP strategy. In particular, under CP strategy, with the increase of inconvenience cost $k$, sales volume through online direct sales channel decreases but the profits increase. On the contrary, sales volume through offline physical retail channel increases but the corresponding profits decrease. This fluctuation is caused by the increase of inconvenience cost $k$ that gives more power to the supplier on channel choices to enable it to gain more profits.

\section{Discussion AND CONCLUSION}

\subsection{Summary of key findings}

This study focuses on the consumers' behavior when faced with different service levels of online direct sales channel and offline physical retail channel. Consumers are divided into different groups on the basis of their preference for convenience, consumption time in the online direct sales channel and the probability of shortage 

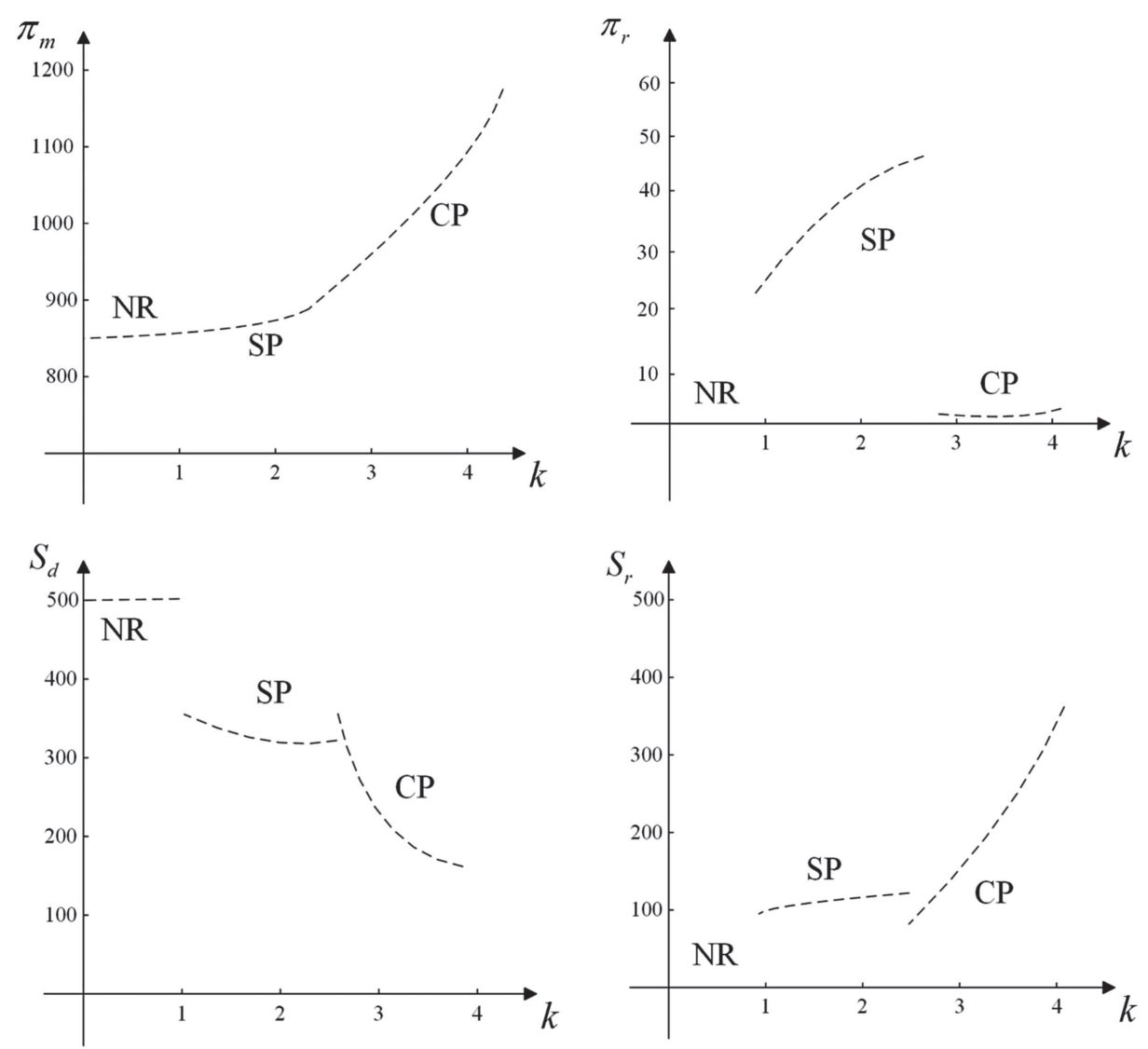

FigURE 6. Influences of inconvenience cost $k$ on profits and sales volume.

in the offline physical retail channel are introduced, and the channel decision-making of fresh agricultural supply chain members is discussed. An assumption model of channel decision-making is proposed in this paper based on consumers' convenience preference and out-of-stock cost in physical stores, which is analyzed using backward induction method to obtain the optimal wholesale price, consumption time of fresh produce suppliers and the service level of retail stores.

The results show that with the increase of consumer utility, the fresh produce supplier will build both online direct sales channel and offline physical channel. With the decrease of cost, the fresh produce supplier will adopt CP strategy. Also, the revenue of physical retailer will increase with the loss of out-of-stock when SP strategy is adopted. When the fresh produce supplier adopts CP strategy, the revenue of physical retailer will remain at a relatively low level. However, the number of products sold through this channel will increase with the increase of out-of-stock losses. Meanwhile, with the increase of out-of-stock losses, the wholesale price of fresh produce will decrease, while the service level and consumption time will increase.

In summary, when making supply chain channel decisions, enterprises must consider market environment factors such as local consumers' convenience preference, consumption time, and service level of physical stores.

\subsection{Theoretical and managerial implications}

From the theoretical perspective, the research on supply chain channels of enterprises is extended to a specific industry. The convenience preference of consumers and the service level of offline retailer are introduced into the 
consumer utility function to explore the decisions of supply chain members. Combined with the characteristics of fresh produce and consumer convenience preferences, the supply chain channel choices decision-making for fresh agricultural enterprises to expand their markets are discussed. There is currently little research in this field.

As the pace of life accelerates and leisure preferences rise, consumers' disposable time is being squeezed considerably. It can be seen that the increasing opportunity cost of time for some consumers has led to higher demands for the convenience of buying fresh produce. Furthermore, with the increasing utility value obtained by consumers from the process of purchasing fresh produce, the channel decision-making of fresh agriculture suppliers should be shifted from the simple establishment of online direct sales channel or offline physical channel to the simultaneous establishment of online and offline channels. For example, suppliers such as Yonghui supermarket, which specializes in offline physical channels, have also established online direct sales channels to improve the consumers' shopping experience. However, with the reduction of the unit cost of fresh produce and the generation of scale benefits, the overall profit of supply chain channel is gradually transferred to fresh agricultural suppliers, and the channel strategy should be changed from SP strategy to CP strategy. Meanwhile, with the decrease of the retail price of fresh produce, the demand will increase. In order to better compete for the market, the channel strategy of fresh agricultural suppliers should be shifted from NR strategy to SP or CP strategy to expand the market.

Therefore, this study provides supply chain channel decision-making for fresh produce companies facing a complex market environment, and helps them to maximize the overall profitability of the supply chain.

\subsection{Limitations and future research opportunities}

Although the markets factors considered in this study are consistent with the actual market, there are still several interesting topics worth of future research. Firstly, this paper does not consider the transfer of consumer preferences when segmenting consumers according to their convenience preferences, which is a topic to be further, studied. Secondly, to simplify the model, this paper assumes that the effect of consumption time on consumer utility is linear, and does not discuss the decline in consumer utility over time, which may also be an opportunity for future research.

\section{Appendix A.}

Proof of Lemma 4.2. Lemma 4.1 can show that the market demand of a retailer in a physical store is $D_{r}$, which is defined as $\left(1-d_{1}\right) X$. Therefore, market demand is evenly distributed in the interval $\left[0, a\left(1-d_{1}\right)\right]$. To guarantee service level $\alpha$, inventory must be $q$ units and the probability should be $\operatorname{Pr}\left(D_{r} \leq q\right)=\alpha$. Thus, we can obtain $q(\alpha)=\operatorname{Pr}\left(D_{r} \leq q\right) \times a\left(1-d_{1}\right)=a \alpha\left(1-d_{1}(\alpha)\right)$.

Function $\varphi(\alpha)$ indicates the level of probability that a consumer can achieve his or her needs in a physical store. Thus,

$$
\begin{aligned}
\varphi(\alpha) & =\operatorname{Pr}(\text { find })=E\left[\operatorname{Pr}\left(\text { find } \mid D_{r}\right)\right] \\
& =\int_{z=0}^{a\left(1-d_{1}(\alpha)\right)} \operatorname{Pr}\left(\text { find } \mid D_{r}=z\right) \times \frac{1}{a\left(1-d_{1}(\alpha)\right)} \mathrm{d} z \\
& =\int_{z=0}^{q} \frac{1}{a\left(1-d_{1}(\alpha)\right)} \mathrm{d} z+\int_{z=q}^{a\left(1-d_{1}(\alpha)\right)} \frac{q}{z} \times \frac{1}{a\left(1-d_{1}(\alpha)\right)} \mathrm{d} z \\
& =\alpha(1-\ln (\alpha)) .
\end{aligned}
$$

That is, $\varphi(\alpha)=\alpha(1-\ln (\alpha))$. 
The following can be deduced from the effective utility value function (4.1) and (4.2):

$$
\begin{aligned}
E\left[\min \left\{D_{r}, q\right\}\right] & =\int_{0}^{a \alpha\left(1-d_{1}(\alpha)\right)} z \frac{1}{a\left(1-d_{1}(\alpha)\right)} \mathrm{d} z+\int_{a \alpha\left(1-d_{1}(\alpha)\right)}^{a\left(1-d_{1}(\alpha)\right)} a \alpha\left(1-d_{1}(\alpha)\right) \frac{1}{a\left(1-d_{1}(\alpha)\right)} \mathrm{d} z \\
& =a\left(1-d_{1}(\alpha)\right)\left(\alpha-\alpha^{2} / 2\right) .
\end{aligned}
$$

When $q(\alpha)=a \alpha\left(1-d_{1}(\alpha)\right)$, we can simplify the formula above and come to $E\left[\min \left\{D_{r}, q\right\}\right]=a\left(1-d_{1}(\alpha)\right)(\alpha-$ $\left.\alpha^{2} / 2\right)=q\left(1-\frac{\alpha}{2}\right)$.

Proof of Proposition 4.3. The process is divided into four steps. First, the value of $\alpha$ should be obtained to make $\pi_{r}(\alpha)=0$. Second, we should prove that $\pi_{r}(\alpha)$ has the only local optimal solution $\alpha_{i}$. Third, local optimal solution $\alpha_{i}$ is compared with the boundary value 0 or $\alpha_{\min }$ and obtain the overall optimal solution $\alpha^{*}$. Fourth, we prove that the overall optimal solution $\alpha^{*}$ will decrease with the increase of wholesale price $\omega$.

Equation (4.8) shows that $\pi_{r}(\alpha)$ will be 0 if $\alpha$ can satisfy that $\alpha_{1}=2(p-w) / p<2$ and $d_{1}(\alpha)=1$. Moreover, when $\alpha \rightarrow 0^{+}, \lim \pi_{r}(\alpha)=0$. From equation (4.5), when $d_{1}(\alpha)=1, \varphi(\alpha)=\frac{v-p+k-t}{v-p}$. By combining with Lemma 4.2, we can draw that $\alpha(1-\ln (\alpha))=\frac{v-p+k-t}{v-p}$. For $\varphi(\alpha)=\alpha(1-\ln (\alpha))$, the derivations can obtain $\frac{\partial \varphi(\alpha)}{\partial \alpha}=-\ln (\alpha)$. Thus, when $\alpha \in(0,1), \varphi(\alpha)$ is an increasing function when $\alpha \in(1,+\infty), \varphi(\alpha)$ is a decreasing function and $\varphi(\alpha)$ can obtain its maximum while $\alpha=1$. In addition, $\lim _{\alpha \rightarrow 0^{+}} \varphi(\alpha)=0$ can be observed when $\alpha=e, \varphi(\alpha)=0$. Therefore, $\varphi(\alpha)<0$ when $\alpha_{2} \in(e,+\infty) ; \varphi(\alpha)>0$ when $\alpha_{3} \in(0,1)$ or $\alpha_{4} \in(1, e)$.

Thus, the value that can make $d_{1}(\alpha)=1$ is in the range of $\alpha_{2} \in(e,+\infty)$ when $v-p+k-t<0$. The value that can make $d_{1}(\alpha)=1$ or $\alpha_{4} \in(1, e)$ is in the range of $\alpha_{3} \in(0,1)$ when $v-p+k-t \geq 0$ and $t \neq k$. The physical stores do not exist when $t=k$ because it is in a no-retailer (NR) equilibrium state; $\pi_{r}(\alpha)$ will be analyzed as follows. From equation (4.9), $\lim _{\alpha \rightarrow \infty} \varphi(\alpha)=\infty$. By taking the derivations,

$$
\frac{\partial \varphi(\alpha)}{\partial \alpha}=\frac{a}{t}\{(p-\omega-p \alpha)[t-k-(1-\alpha)(v-p)]-(v-p) \alpha \ln (\alpha)[2(p-w)-3 \alpha p / 2]\} .
$$

To find the limit value, $\lim _{\alpha \rightarrow 0^{+}} \frac{\partial \pi_{r}(\alpha)}{\partial \alpha}=\frac{a}{t}[(p-\omega)(t-k-v+p)]$. Similarly, the three-order and four-order derivatives of $\pi_{r}(\alpha)$ are calculated. We can then obtain:

$$
\begin{aligned}
\frac{\partial^{3} \pi_{r}(\alpha)}{\partial \alpha^{3}} & =\frac{a(v-p)}{t}\left[\frac{5}{2} p-\frac{2(p-\omega)}{\alpha}+3 p \ln (\alpha)\right] . \\
\frac{\partial^{4} \pi_{r}(\alpha)}{\partial \alpha^{4}} & =\frac{a(v-p)}{t}\left[\frac{3}{2} p+\frac{2(p-\omega)}{\alpha^{2}}\right] .
\end{aligned}
$$

Evidently, $\frac{\partial^{4} \pi_{r}(\alpha)}{\partial \alpha^{4}}>0, \lim _{\alpha \rightarrow 0^{+}} \frac{\partial^{3} \pi_{r}(\alpha)}{\partial \alpha^{3}}<0$, and $\lim _{\alpha \rightarrow+\infty} \frac{\partial^{3} \pi_{r}(\alpha)}{\partial \alpha^{3}}>0$. Thus, the curve of $\frac{\partial^{2} \pi_{r}(\alpha)}{\partial \alpha^{2}}$ will descend first and then rise, that is, $\frac{\partial^{2} \pi_{r}(\alpha)}{\partial \alpha^{2}}$ has a unique minimum point, which means that $\frac{\partial \pi_{r}(\alpha)}{\partial \alpha}$ has a maximum of three zero points.

When $v-p+k-t<0, \lim _{\alpha \rightarrow 0^{+}} \frac{\partial \pi_{r}(\alpha)}{\partial \alpha}>0$. At this time, $\pi_{r}(\alpha)$ has two zero points: $\alpha_{1}=2(p-\omega) / p$ and $\alpha_{1}>e$. Thus, $\pi_{r}(\alpha) \geq 0$ in the range of $\left(0, \alpha_{1}\right)$ and $\left(\alpha_{2},+\infty\right) ; \pi_{r}(\alpha) \leq 0$ in the range of $\left(\alpha_{1}, \alpha_{2}\right)$. This finding means that $\pi_{r}(\alpha)$ will have at least one local maximum at the range of $\alpha_{i} \in\left(0, \alpha_{1}\right)$ and at least one local minimum at the range of $\alpha_{j} \in\left(\alpha_{1}, \alpha_{2}\right) . \alpha_{i}$ and $\alpha_{j}$ are its special points. If another local maximum (minimum) exists, a corresponding local minimum (maximum) will exist, which means that $\pi_{r}(\alpha)$ has four positive limit values. This finding is against the deduction of $\frac{\partial \pi_{r}(\alpha)}{\partial \alpha}$, which has a maximum of three zero points. Thus, $\pi_{r}(\alpha)$ has only one local maximum at $\alpha_{i} ; \alpha_{i} \in\left(0, \alpha_{1}\right)$.

When $v-p+k-t \geq 0, \lim _{\alpha \rightarrow 0^{+}} \frac{\partial \pi_{r}(\alpha)}{\partial \alpha}<0$. At this time, $\pi_{r}(\alpha)$ has three zero points: $\alpha_{1}=2(p-\omega) / p$, $\alpha_{3}<1$, and $\alpha_{4} \in(1, e)$. Five situations are taken by considering $\alpha_{1}=2(p-\omega) / p$ : (1) $\alpha_{1}<\alpha_{3}<\alpha_{4}<e ;(2)$ $\alpha_{1}=\alpha_{3}<\alpha_{4}<e ;(3) \alpha_{3}<\alpha_{1}<\alpha_{4}<e$; (4) $\alpha_{3}<\alpha_{1}=\alpha_{4}<e ;(5) \alpha_{3}<\alpha_{4}<\alpha_{1}<e$. In these situations, $\pi_{r}(\alpha)$ has one local maximum $\alpha_{i}$, two local minimum $\alpha_{j_{1}}$ and $\alpha_{j_{2}}, \alpha_{j_{1}}<\alpha_{i}<\alpha_{j_{2}} ; \pi_{r}(\alpha)$ has a maximum of 
three limit points; hence, other limit points will not exist. Thus, $\pi_{r}(\alpha)$ has only one local maximum at $\alpha_{i}$ and $\alpha_{i} \in\left(0, \max \left\{\alpha_{1}, \alpha_{3}\right\}\right)$.

According to the discussions presented above, the optimal reaction of physical store retailer $\alpha^{*}$ is equal to $\alpha_{i}$ or one of $\alpha_{\min }$ and 1. Set $\alpha_{\max }=\max \left\{\alpha \mid \pi_{\alpha}=0\right\}$, when $v-p+k-t<0, \alpha_{\max }=\alpha_{2}>e \cong 2.71>1$; $\alpha_{\max }=\max \left\{\alpha_{1}, \alpha_{4}\right\}>1$ when $v-p+k-t \geq 0$. Regardless of situation, $\alpha_{\max }>1$, so $\alpha^{*} \in\left(\alpha_{\max }, \infty\right)$ does not exist, which means $\alpha^{*}$ cannot be in the right end of the ascending area of $\pi_{r}(\alpha)$ because this area is not in the range of $\left[\alpha_{\min }, 1\right]$. When the profit of the physical stores will not be negative, the corresponding solution of the constraint in equation (4.9) is $\alpha_{i}$ or one of $\alpha_{\min }$ and 1. If the profit of the optimal reaction of physical store retailer is negative in $\alpha \in\left[\alpha_{\min }, 1\right]$, then the retailer will set $\alpha^{*}=\alpha_{0}$ and decide not to order any product from the supplier; in this case, $\pi_{r}\left(\alpha^{*}=\alpha_{0}\right)=0$.

By deviating $\pi_{r}(\alpha)$ by $\alpha$ and $\omega$, we can obtain

$$
\frac{\partial^{2} \pi_{r}(\alpha)}{\partial \alpha \partial \omega}=\frac{a\{-t+k+(v-p)[1-\alpha(1-2 \ln (\alpha))]\}}{t} .
$$

$t \geq t^{e}=k+(v-p)\{1-\alpha[1-\ln (\alpha)]\}$, so we can know that $\frac{\partial^{2} \pi_{r}(\alpha)}{\partial \alpha \partial \omega}<0$, and $\alpha^{*}$ will decrease with the increase of wholesale price $\omega$. This imbalance will always exist because the supplier will not set $t<t^{e}$ in the equilibrium.

Proof of Corollary 4.4. From equation (4.9), we can obtain $\lim \pi_{r}(\alpha, t)=a \alpha\left(p-\omega-\frac{\alpha p}{2}\right)$. By considering $\alpha=(p-\omega) / p$ and the lowest service level that the physical store retailer must supply, we can obtain $\lim _{t \rightarrow \infty} \alpha^{*}(t)=\max \left\{\alpha_{\min }, \frac{p-\omega}{p}\right\}$.

Proof of Lemma 4.5. The distribution of different types of demand under different market parameters is presented in Lemma 4.1. The optional order size of physical store retailer, which is, $q(\alpha)=a \alpha\left(1-d_{1}(\alpha)\right)$ is shown in Lemma 4.2. The combination of Lemmas 4.1 and 4.2 shows the expected sales of direct channel, for example, when $t \in\left(t^{e}, v-p\right]$, we can deduce that

$$
E\left(D_{d}^{1}+D_{d}^{2}\right)=E\left[d_{1} X\right]+E\left[\left(1-d_{1}\right) X-q\right]^{+}=d_{1}\left(\frac{\alpha}{2}\right)+\int_{q=a \alpha\left(1-d_{1}(\alpha)\right)}^{a\left(1-d_{1}(\alpha)\right)} \frac{(z-q)}{a\left(1-d_{1}\right)} \mathrm{d} z .
$$

By considering different market segments, we can deduce the expected sales of the direct channel:

$$
E\left(D_{d}^{1}+D_{d}^{2}\right)=\left\{\begin{array}{ll}
\frac{a}{2} & t \leq t^{e} \\
\frac{a}{2}[\alpha(\alpha-2)+1]-\frac{a}{2 t}(\alpha-2)((v-p)[1-\phi(\alpha)]+k) & t \in\left(t^{e}, v-p\right] \\
\frac{a}{2 t}\{\alpha(\alpha-2)[(v-p) \phi(\alpha)-k]+(v-p)\} & t \in(v-p, \infty) \\
0 & t \rightarrow \infty
\end{array} .\right.
$$

Finally, we plug $E\left(D_{d}^{1}+D_{d}^{2}\right), q(\alpha)=a \alpha\left(1-d_{1}(\alpha)\right)$, and $\phi(\alpha)=\alpha(1-\ln (\alpha))$ into equation (4.10). We can then obtain the expected return function of manufacturers.

Proof of Lemma 4.6. Derive $\pi_{m}^{a}(t)$ by $t$ and we can obtain $\frac{\partial \pi_{m}^{a}(t)}{\partial t}=\frac{1}{t^{2}}\left(\frac{2 m}{t}-G^{a}(\alpha)\right)$. By setting $\frac{\partial \pi_{m}^{a}(t)}{\partial t}=0$, $t_{f}^{a}=\frac{2 m}{G^{a}(\alpha)}$. When $G^{a}(\alpha) \leq 0$, in the range of $t \in(0, \infty), \frac{\partial \pi_{m}^{a}(t)}{\partial t} \geq 0$, that is, $\pi_{m}^{a}(t)$ is an increasing function of delivery lead time $t$. When $G^{a}(\alpha)>0$, in the range of $t \in\left(0, t_{f}^{a}\right), \frac{\partial \pi_{m}^{a}(t)}{\partial t}>0$ and if $t \in\left(t_{f}^{a}, \infty\right), \frac{\partial \pi_{m}^{a}(t)}{\partial t}<0$. $\pi_{m}^{a}(t)$ is a function of $\alpha$ with unimodal distribution, which will have the maximum point while $t_{f}^{a}=\frac{2 m}{G^{a}(\alpha)}$. 
Proof of Proposition 4.7. According to Lemma 4.5, the expected return function of the manufacturer is a continuous function. To better describe $t^{*}$, we study the expected return function of the manufacturer in three different ranges. First, $G^{u}(\alpha) \geq G^{a}(\alpha)$ should be noted. On the basis of this finding, three situations are discussed.

Situation 1. When $G^{u}(\alpha) \geq G^{a}(\alpha)>0, t_{f}^{a} \geq t_{f}^{u}$,

(1) When $t_{f}^{a} \in\left(0, t^{e}\right]$ and $t_{f}^{u} \leq v-p$, from Lemmas 4.5 and 4.6, $\pi_{m}^{e}(t)$ is an increasing function when $t \in\left(0, t^{e}\right]$ and obtains its maximum $\pi_{m}^{e}\left(t^{e}\right)$ at the point of $t^{e} \cdot \pi_{m}^{a}(t)$ and $\pi_{m}^{u}(t)$ are the decreasing functions of $t$ in this range, so $\pi_{m}(t)$ will have the highest profit at the point of $t^{e}, t^{*}=t^{e}$.

(2) When $t_{f}^{a} \in\left(t^{e}, v-p\right]$ and $t_{f}^{u} \leq v-p, \pi_{m}^{e}(t)$ is an increasing function when $t \in\left(0, t^{e}\right], \pi_{m}^{a}(t)$ is an increasing function when $t \in\left(t^{e}, t_{f}^{a}\right]$ and a decrease function when $t \in\left(t_{f}^{a}, v-p\right]$, and $\pi_{m}^{u}(t)$ is a decreasing function when $t \in(v-p, \infty)$. Thus, $\pi_{m}(t)$ will have the highest profit at the point of $t_{f}^{a}, t^{*}=t_{f}^{a}$.

(3) When $t_{f}^{a} \in(v-p, \infty)$ and $t_{f}^{u} \leq v-p, \pi_{m}^{e}(t)$ is an increasing function when $t \in\left(0, t^{e}\right], \pi_{m}^{a}(t)$ is an increasing function when $t \in\left(t^{e}, v-p\right]$, and $\pi_{m}^{u}(t)$ is a decreasing function when $t \in(v-p, \infty)$. Thus, $\pi_{m}(t)$ will have the highest profit at the point of $v-p, t^{e}=v-p$.

(4) When $t_{f}^{a} \in\left(0, t^{e}\right]$ and $t_{f}^{u}>v-p$, this sub-situation will not exist. At this time, $t_{f}^{a}<t_{f}^{u}$, which is against the conclusion of Situation 1. The sub-situation will not exist when $t_{f}^{a} \in\left(t^{e}, v-p\right]$ and $t_{f}^{u}>v-p$ because of the same reason.

(5) When $t_{f}^{a} \in(v-p, \infty)$ and $t_{f}^{u}>v-p, \pi_{m}^{e}(t)$ is an increasing function when $t \in\left(0, t^{e}\right], \pi_{m}^{a}(t)$ is an increasing function when $t \in\left(t^{e}, v-p\right]$, and $\pi_{m}^{u}(t)$ is an increasing function when $t \in\left(v-p, t_{f}^{u}\right]$ and a decreasing function when $t \in\left(t_{f}^{u}, \infty\right)$. Thus, $\pi_{m}(t)$ will have the highest profit at the point of $t_{f}^{u}, t^{*}=t_{f}^{u}$.

Situation 2. When $G^{u}(\alpha)>0 \geq G^{a}(\alpha), \pi_{m}^{e}(t)$ is an increasing function when $t \in\left(0, t^{e}\right]$, and $\pi_{m}^{a}(t)$ is an increasing function when $t \in\left(t^{e}, v-p\right]$. At this time, if $t_{f}^{u}>v-p$, then $t^{*}=t_{f}^{u}$; otherwise, $t^{*}=v-p$ because $\pi_{m}^{u}(t)$ is a decreasing function when $t \in\left(t_{f}^{u}, \infty\right)$.

Situation 3. When $0 \geq G^{u}(\alpha) \geq G^{a}(\alpha), \pi_{m}^{e}(t), \pi_{m}^{a}(t)$ and $\pi_{m}^{u}(t)$ are the increasing functions of $t ; \pi_{m}(t)$ will attain the highest profit at the maximum point of $t$.

Acknowledgements. This work was supported by National Natural Science Foundation of China (71871098), Humanities and Social Sciences Research Planning Fund Project of the Ministry of Education (18YJA630127), Soft Science Research Project of Guangdong Province (2019A101002119), and Natural Science Foundation of Guangdong Province (2017A030313415).

\section{REFERENCES}

[1] A. Balakrishnan, S. Sundaresan and B. Zhang, Browse-and-switch: retail-online competition under value uncertainty. Prod. Oper. Manage. 23 (2014) 1129-1145.

[2] L.L. Berry, K. Seiders and D. Grewa, Understanding service convenience. J. Marketing 66 (2002) 1-17.

[3] E. Cao, Coordination of dual-channel supply chains under demand disruptions management decisions. Int. J. Prod. Res. 52 (2014) $7114-7131$.

[4] X. Cai, J. Chen, Y. Xiao and X. Xu, Optimization and coordination of fresh product supply chains with freshness-keeping effort. Prod. Oper. Manage. 19 (2010) 261-278.

[5] K.Y. Chen, M. Kaya and Ö. Özer, Dual sales channel management with service competition. Manuf. Serv. Oper. Manage. 10 (2008) 654-675.

[6] J. Correa, R. Montoya and C. Thraves, Contingent preannounced pricing policies with strategic consumers. Soc. Sci. Electr. Publ. 64 (2012) 251-272.

[7] B. Dan, C. Liu, G. Xu and X. Zhang, Pareto improvement strategy for service-based free-riding in a dual-channel supply chain. Asia-Pac. J. Oper. Res. 31 (2014) 1450050.

[8] A. Dumrongsiri, M. Fan, A. Jain and K. Moinzadeh, A supply chain model with direct and retail channels. Eur. J. Oper. Res. 187 (2008) 691718.

[9] S. Gensler, P.C. Verhoef and M. Böhm, Understanding consumers' multichannel choices across the different stages of the buying process. Marketing Lett. 23 (2012) 987-1003.

[10] A. Ha, L. Li and S. Ng, Price and delivery logistics competition in a supply chain. Manage. Sci. 49 (2003) 11391153. 
[11] T. Javadi, N. Alizadeh-Basban, S. Asian and A. Hafezalkotob, Pricing policies in a dual-channel supply chain considering flexible return and energy-saving regulations. Comput. Ind. Eng. 135 (2019) 655-674.

[12] M.M. Khudri and S. Sultana, Determinants of service quality and impact of service quality and consumer characteristics on channel selection. Br. Food J. 117 (2015) 2078-2097.

[13] Y. Lan, Y. Li and F. Papier, Competition and coordination in a three-tier supply chain with differentiated channels. Eur. J. Oper. Res. 269 (2018) 870-882.

[14] B. Li, M. Zhu, Y. Jiang and Z. Li, Pricing policies of a competitive dual-channel green supply chain. J. Cleaner Prod. 112 (2016) 2029-2042.

[15] Q. Li, B. Li, P. Chen and P. Hou, Dual-channel supply chain decisions under asymmetric information with a risk-averse retailer. Ann. Oper. Res. 257 (2017) 423-447.

[16] T. Li, X. Zhao and J. Xie, Inventory management for dual sales channels with inventory-level-dependent demand. J. Oper. Res. Soc. 66 (2015) 488-499.

[17] Q. Liu and D. Zhang, Dynamic pricing competition with strategic customers under vertical product differentiation. Manage. Sci. 59 (2013) 84-101.

[18] M. Maity and M. Dass, Consumer decision-making across modern and traditional channels: E-commerce, m-commerce, in-store. Decis. Support Syst. 61 (2014) 34-46.

[19] H. Oppewal, D.R. Tojib and P. Louvieris, Experimental analysis of consumer channel-mix use. J. Bus. Res. 66 (2013) 22262233.

[20] C. Patel, Successful service retail channel expansions: the roles of technical and brand integration. Ind. Marketing Managem. 43 (2014) 102-112.

[21] L. Ren, Y. He and H. Song, Price and service competition of dual-channel supply chain with consumer returns. Discrete Dyn. Nat. Soc. 11 (2014) 110.

[22] F. Soleimani, A.A. Khamseh and B. Naderi, Optimal decisions in a dual-channel supply chain under simultaneous demand and production cost disruptions. Ann. Oper. Res. 243 (2016) 1-21.

[23] L.M. Sonderegger-Wakolbinger and C. Stummer, An agent-based simulation of customer multi-channel choice behavior, Cent. Eur. J. Oper. Res. 23 (2015) 459-477.

[24] X. Su and F. Zhang, Strategic customer behavior, commitment, and supply chain performance. Manage. Sci. 54 (2007) 1759-1773.

[25] L. Wang, H. Song and Y. Wang, Pricing and service decisions of complementary products in a dual-channel supply chain. Comput. Ind. Eng. 105 (2017) 223-233.

[26] T. Xiao and J. Shi, Pricing and supply priority in a dual-channel supply chain. Eur. J. Oper. Res. 254 (2016) 813823.

[27] S. Yan, Z.S. Hua and Y.W. Bian, Does retailer benefit from implementing "online-to-store" channel in a competitive market? IEEE Trans. Eng. Manage. 67 (2020) 496-512.

[28] X. Zhao, K. Stecke and A. Prasad, Lead time and price quotation mode selection: uniform or differentiated? Prod. Oper. Manage. 21 (2011) 177-193. 